\title{
Ultrasound, endoscopy, and the recurrent nerve
}

\author{
Scott M. Bradley, MD
}

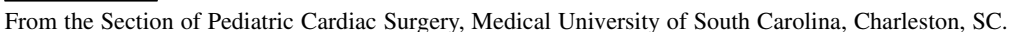

Disclosures: Author has nothing to disclose with regard to commercial support.

Received for publication Jan 13, 2018; accepted for publication Jan 23, 2018; available ahead of print March 9, 2018.

Address for reprints: Scott M. Bradley, MD, Pediatric Cardiac Surgery, Medical University of South Carolina,

CSB 424, 96 Jonathan Lucas St, Charleston, SC 29425 (E-mail: bradlesm@musc.edu).

J Thorac Cardiovasc Surg 2018;155:2588-90

$0022-5223 / \$ 36.00$

Copyright $(2) 2018$ by The American Association for Thoracic Surgery

https://doi.org/10.1016/j.jtcvs.2018.01.043

Recurrent laryngeal nerve injury is a common and important complication of aortic arch surgery in infants. Arch reconstruction requires mobilization of the nerve as it loops around the aorta and the ductus arteriosus (Figure 1). The recurrent laryngeal nerves innervate the intrinsic muscles of the larynx, which open, close, and adjust the tension of the vocal cords. The nerves also provide sensory innervation to the larynx below the level of the vocal cords, as well as some sensory, secretory, and motor function to the cervical esophagus and trachea. Recurrent nerve injury results in lack of both abduction and adduction of the ipsilateral vocal cord, which is immobilized in a paramedian position. The clinical results can include a weak or hoarse cry, stridor, disrupted swallowing, inadequate cough and clearance of secretions, and aspiration. The criterion standard for identification of vocal cord mobility is direct visualization by flexible fiberoptic nasoendoscopy. Endoscopy demonstrates not only vocal cord motion but also the presence of laryngeal edema, laryngomalacia, and a glottic gap (which is usually accompanied by aspiration). It is important to identify recurrent nerve injury, because it has been shown to be associated with swallowing dysfunction and need for tube feedings, ${ }^{1}$ aspiration, ${ }^{2,3}$ and poor interstage growth. ${ }^{4}$ The presence of left recurrent nerve injury also means that future surgery in the right side of the neck, such as for extracorporeal membrane oxygenation cannulation, will place the patient at risk for contralateral nerve injury, with resultant bilateral cord paralysis and the potential need for tracheostomy.

Feeding intolerance is a related morbidity in infants of aortic arch surgery, particularly the Norwood procedure. Establishment of adequate oral intake is frequently a difficult task for patients who have undergone the Norwood procedure. Data from the Pediatric Heart Network Single Ventricle Reconstruction Trial showed that only $32 \%$ of patients who had undergone the Norwood procedure were taking full oral feedings by the time of discharge. ${ }^{5}$ Feeding intolerance results in prolonged hospital stay, need for gastrostomy placement, malnutrition, and poor interstage growth. Aspiration of feedings may contribute to mortality, both perioperative and interstage. Recurrent nerve injury is

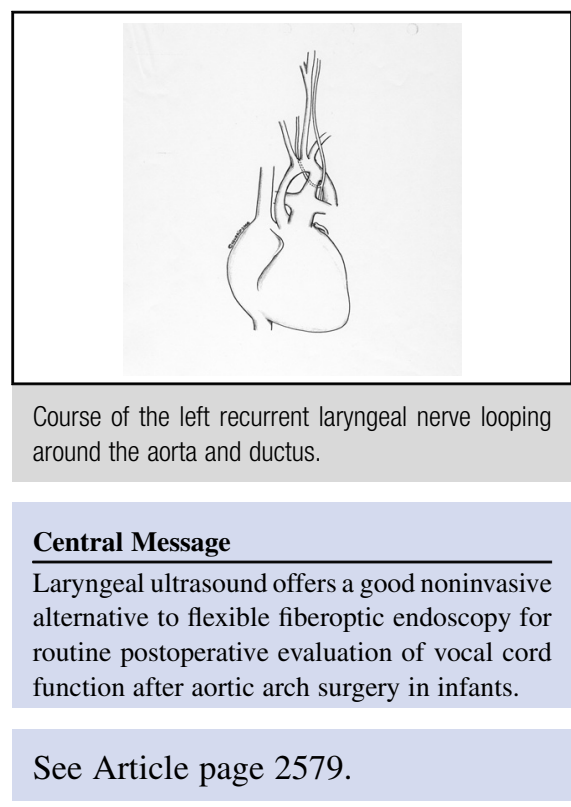

one of several factors that can contribute to feeding intolerance; others include the hemodynamic burden of the parallel single ventricle circulation, ${ }^{6}$ alterations in mesenteric blood flow, ${ }^{7}$ a complex or prolonged perioperative course, anatomic issues (ventricular dysfunction and atrioventricular valve regurgitation), and genetic factors. ${ }^{3,8,9}$

In 2003, our group initiated routine evaluation of recurrent nerve and swallowing function in infants after aortic arch surgery. ${ }^{2}$ Evaluation is carried out for any infant undergoing either a Norwood procedure or aortic arch reconstruction through a sternotomy as part of a biventricular repair. Vocal cord function is evaluated by endoscopy carried out by a pediatric otolaryngologist after endotracheal extubation. Swallowing function is evaluated by videofluoroscopic modified barium swallow under the direction of a speechlanguage pathologist and pediatric radiologist. The swallow study provides detailed information on multiple components of swallowing physiology, aspiration in particular. ${ }^{10}$ Because aspiration in infants is frequently clinically silent, identification requires objective evaluation. The results of the evaluations are used to guide feeding advancement, thickening of feedings, and need for placement of a gastrostomy tube. My latest analysis of this protocol included 153 infants who had undergone 95 Norwood procedures and 58 biventricular arch repairs. The incidences of left vocal cord paralysis were $16 \%$ after the Norwood procedure and $22 \%$ after biventricular arch repair. The incidences of aspiration were $28 \%$ after the Norwood procedure and $40 \%$ after biventricular arch repair. Vocal cord paralysis was associated 


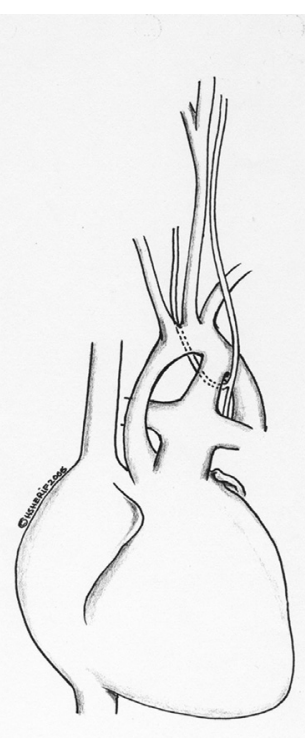

FIGURE 1. Course of the left recurrent laryngeal nerve looping around the aorta and ductus.

with, but incompletely overlapped with aspiration. Among patients with vocal cord paralysis, $43 \%$ also had aspiration, whereas $57 \%$ did not. Among those with aspiration, $75 \%$ had normal vocal cord function. The incomplete overlap of nerve injury with feeding function has also been reported by others. ${ }^{3}$ Nerve injury should be regarded as permanent in most cases; follow-up endoscopy in our cohort showed persistent vocal cord paralysis in $61 \%$. Other groups who have routinely evaluated vocal cord function after arch surgery in infants have reported an incidence of nerve injury ranging from $34 \%$ to $73 \%$. $1,3,8,11-13$

In this issue of the Journal, Lee and colleagues ${ }^{14}$ from the Royal Children's Hospital, Melbourne, report the use of laryngeal ultrasound to evaluate vocal cord function after aortic arch surgery in infants. Their study includes 52 infants who underwent either a Norwood procedure (in 13 cases) or other aortic arch repair through a sternotomy (in 39 cases). Laryngeal ultrasound demonstrated left vocal cord paresis (either decreased or no movement) in 59\% of the patients. A subset of these patients also underwent flexible endoscopy. The correlation between ultrasound and endoscopy was very high (almost exact). Ultrasound examination had a fairly low failure rate of $8 \%$. The ultrasound findings are easily appreciated in the accompanying videos.

This study is the first systematic evaluation of laryngeal ultrasound in infants after aortic arch surgery. The comparison with the criterion standard of endoscopy is a strength of the study, and the correlation between the approaches provides convincing support for ultrasound as an appropriate alternative to endoscopy. A limitation of the study is the inclusion of just fewer than half of potential participants because of lack of consent. Furthermore, within the study population, roughly $25 \%$ did not contribute to the endoscopy comparison. It seems unlikely, however, that these limitations significantly affected the study's findings. Lee and colleagues ${ }^{14}$ also found that clinical findings alone (primarily stridor and a weak cry) are suggestive of vocal cord dysfunction but give an incomplete picture, with both false positives and false negatives. I agree with their conclusion that accurate assessment of the incidence of recurrent nerve injury requires direct examination (with either endoscopy or ultrasound) in all cases.

The incidence of vocal cord dysfunction in this study lies at the high end of previous studies, ${ }^{1-3,8,11-13}$ which highlights the importance of surgical technique. This generally means using blunt dissection rather than cautery in the region of the nerve, which has been demonstrated to reduce nerve injury. ${ }^{1}$ Bipolar cautery is another alternative. In this study, Lee and colleagues ${ }^{14}$ investigated the technique of skeletonization and posterior relocation of the nerve in 14 patients; however, this approach carried a $64 \%$ incidence of nerve injury.

Given the high incidence of recurrent laryngeal nerve injury and its impact on clinical outcome, a good argument can be made that routine evaluation after arch surgery in infants should be standard of care. Flexible endoscopy is generally carried out without sedation and is a fairly benign procedure. Nonetheless, laryngeal ultrasound may be better tolerated, and it appears to offer a good noninvasive alternative. The technique seems straightforward and could potentially be adopted by any clinician with ultrasound skills, including intensivists. Its application could also be expanded to other patients, such as those who have undergone coarctation repair or ductal ligation through a thoracotomy. These are groups in whom the true incidence of nerve injury has not been well characterized but may be as high as $50 \%{ }^{3,15}$ I congratulate Lee and colleagues ${ }^{14}$ on a novel study with the potential to affect clinical practice.

\section{References}

1. Averin K, Uzark K, Beekman RH III, Willging JP, Pratt J, Manning PB. Postoperative assessment of laryngopharyngeal dysfunction in neonates after Norwood operation. Ann Thorac Surg. 2012;94:1257-61.

2. Skinner ML, Halstead LA, Rubinstein CS, Atz AM, Andrews D, Bradley SM. Laryngopharyngeal dysfunction after the Norwood procedure. J Thorac Cardiovasc Surg. 2005;130:1293-301.

3. Davies RR, Carver SW, Schmidt R, Keskeny H, Hoch J, Pizarro C. Laryngopharyngeal dysfunction independent of vocal fold palsy in infants after aortic arch in terventions. J Thorac Cardiovasc Surg. 2014;148:617-24.e2.

4. Hill GD, Hehir DA, Bartz PJ, Rudd NA, Frommelt MA, Slicker J, et al. Effect of feeding modality on interstage growth after stage I palliation: a report from the National Pediatric Cardiology Quality Improvement Collaborative. J Thorac Cardiovasc Surg. 2014;148:1534-9.

5. Lambert LM, Pike NA, Medoff-Cooper B, Zak V, Pemberton VL, YoungBorkowski L, et al; Pediatric Heart Network Investigators. Variation in feeding practices following the Norwood procedure. J Pediatr. 2014;164 237-42.e1. 
6. Kelleher DK, Laussen P, Teixeira-Pinto A, Duggan C. Growth and correlates of nutritional status among infants with hypoplastic left heart syndrome (HLHS) after stage 1 Norwood procedure. Nutrition. 2006;22:237-44.

7. del Castillo SL, Moromisato DY, Dorey F, Ludwick J, Starnes VA, Wells WJ, et al. Mesenteric blood flow velocities in the newborn with single-ventricle physiology: modified Blalock-Taussig shunt versus right ventricle-pulmonary artery conduit. Pediatr Crit Care Med. 2006;7:132-7.

8. Davies RR, Carver SW, Schmidt R, Keskeny H, Hoch J, Pizarro C. Gastrointestinal complications after stage I Norwood versus hybrid procedures. Ann Thorac Surg. 2013;95:189-95; discussion 195-6.

9. Burnham N, Ittenbach RF, Stallings VA, Gerdes M, Zackai E, Bernbaum J, et al Genetic factors are important determinants of impaired growth after infant cardiac surgery. J Thorac Cardiovasc Surg. 2010;140:144-9.

10. McGrattan KE, McGhee H, DeToma A, Hill EG, Zyblewski SC, Lefton-Greif M, et al. Dysphagia in infants with single ventricle anatomy following stage 1 palliation: physiologic correlates and response to treatment. Congenit Heart Dis. 2017; 12:382-8.
11. Mery CM, Guzmán-Pruneda FA, Carbery KE, Watrin CH, McChesney GR, Chan JG, et al. Aortic arch advancement for aortic coarctation and hypoplastic aortic arch in neonates and infants. Ann Thorac Surg. 2014;98:625-33; discussion 633.

12. Pourmoghadam KK, DeCampli WM, Ruzmetov M, Kosko J, Kishawi S, O'Brien M, et al. Recurrent laryngeal nerve injury and swallowing dysfunction in neonatal aortic arch repair. Ann Thorac Surg. 2017;104:1611-8.

13. Garcia X, Jaquiss RDB, Imamura M, Swearingen CJ, Dassinger MS III, Sachdeva R. Preemptive gastrostomy tube placement after Norwood operation. J Pediatr. 2011;159:602-7.e1.

14. Lee MG, Millar J, Rose E, Jones A, Wood D, Luitingh TL, et al. Laryngeal ultrasound detects a high incidence of vocal cord paresis after aortic arch repair in neonates and young children. J Thorac Cardiovasc Surg. 2018;155: 2579-87.

15. Clement WA, El-Hakim H, Phillipos EZ, Coté JJ. Unilateral vocal cord paralysis following patent ductus arteriosus ligation in extremely low-birth-weight infants. Arch Otolaryngol Head Neck Surg. 2008;134:28-33. 